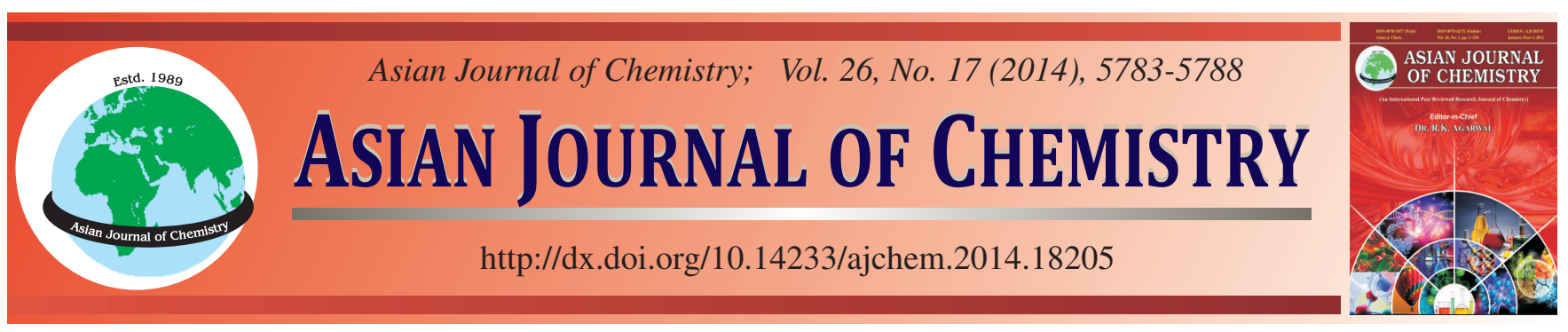

\title{
Numerical Well Testing Interpretation Method of Composite Model and Applications in Offshore Reservoirs by Polymer Flooding $\dagger$
}

\author{
Haiyang Yu ${ }^{1, *}$, Hui Guo ${ }^{1,2}$, Shieing Cheng $^{1}$, Lei $^{1}{ }^{1}$, Shuping Chang ${ }^{1}$, Tiantian Zhang ${ }^{3}$ and Guozhi Feng ${ }^{4}$
}

\author{
${ }^{1}$ MOE Key Laboratory of Petroleum Engineering, China University of Petroleum Beijing, Beijing 102249, P.R. China \\ ${ }^{2}$ The Second Oil Production Plant of North China Branch, SINOPEC, Ningxia 751506, P.R. China \\ ${ }^{3}$ Department of Petroleum Engineering, University of Texas at Austin, Austin 78712, Texas, USA \\ ${ }^{4}$ CNOOC Research Institute, Beijing 100027, P.R. China
}

*Corresponding author: Tel: +86 10 89734978; E-mail: haiyangyu@utexas.edu

\begin{abstract}
This work presents numerical well testing method of composite model for formation evaluation by using pressure transient data, which are provided by CNOOC field tests. Since polymer flooding reservoirs are effected by multiple factors, the well testing composite models are established by considering wellbore storage effect, convection and diffusion. Typical curves, sensitivity analysis and history match are also conducted. In the Newtonian-non-Newtonian composite model, the pressure derivative curves of the transient section and the radial flow section obviously move upward with the increase of polymer viscosity. In the non-Newtonian-Newtonian composite reservoir, the greater of the oil viscosity, the greater magnitude upturned of the transition section. The data of polymer flooding field tests provided by CNOOC indicates that our work can accurately evaluate reservoir characteristics in relatively homogeneous offshore reservoirs by polymer flooding, which emphasizes the potential for the application of this method in relatively homogeneous offshore and onshore reservoirs.
\end{abstract}

Keywords: Well testing, Polymer flooding, Composite model, History match.

\section{INTRODUCTION}

At present, there are many methods researched for EOR, e.g., polymer flooding ${ }^{1}$, surfactant flooding ${ }^{2}$, alkalisurfactant-polymer (ASP) flooding ${ }^{3}$, nanoparticles ${ }^{4,5}$, low salinity water flooding ${ }^{6}$, and $\mathrm{CO}_{2}$ flooding ${ }^{7}$. Among these methods, polymer flooding is the most successful application in oilfields due to its reasonable price and high efficiency ${ }^{8}$. The significant advan-tage of polymer flooding is its high sweep efficiency ${ }^{9}$.

Conventional pressure transient well testing has historically been the main source for formation evaluation, to get the permeability and skin factor. Nowadays, well testing models and techniques in water flooding reservoirs are mature and commercial software can be used for reservoir evaluation. However, well testing models and interpretation methods in reservoirs by polymer flooding need to be further improved.

Ikoku and Ramey ${ }^{10}$ studied the transient flow percolation characteristics of non-Newtonian power law fluids in porous media and achieve the analytic solution in homogeneous infinite reservoirs by taking wellbore storage effect and skin factor into account.
Song et al. ${ }^{11,12}$ developed a well testing model of Newtonian-non-Newtonian composite reservoirs and power law non-Newtonian fluids composite reservoirs.

Hydrolyzed polyacrylamides (HPAM) polymer solution is one kind of non-Newtonian fluids and its viscosity is a significant parameter used to establish well testing interpretation model for polymer flooding. Many researches on the rheological behaviour of polymer solution are simply considering polymer as power law fluid and using constant power exponent model to represent the percolation of polymer solution in reservoirs ${ }^{10-13}$. For polymer flooding reservoirs, there exist not only shear effect and viscoelastic effect but also physicochemical interaction during polymer solution percolating in porous medium. Whereas the constant power exponent viscosity model ignores the interaction between polymers and reservoir rocks, including diffusion and convection. Although these researches are unable to meet the actual demands of our offshore oilfields, they lay a solid foundation for our work.

The purpose of this study is to establish numerical well testing analysis method of composite model which can be applied in offshore reservoirs by polymer flooding, by considering wellbore storage effect, skin factor, convection and diffusion. 


\section{EXPERIMENTAL}

A proprietary hydrolyzed polyacrylamide (degree of hydrolysis $=5 \%, \mathrm{Mw}=5 \times 10^{6} \mathrm{~g} / \mathrm{mol}$ ) used for polymer flooding was obtained from CNOOC. The characteristics of crude oil under surface conditions and reservoir conditions are shown in Tables 1 and 2, respectively. The synthetic brine composition is shown in Table-3.

\begin{tabular}{ccc}
\multicolumn{4}{c}{ TABLE-1 } \\
\multicolumn{3}{|c}{ CHARACTERISTICS OF CRUDE OIL } \\
\multicolumn{3}{c}{ UNDER SURFACE CONDITIONS } \\
\hline $\begin{array}{c}\text { Density } \\
\left(\mathrm{g} / \mathrm{cm}^{3}, 20^{\circ} \mathrm{C}\right)\end{array}$ & $\begin{array}{c}\text { Viscosity } \\
\left(\mathrm{mPa} . \mathrm{s}, 20^{\circ} \mathrm{C}\right)\end{array}$ & $\begin{array}{c}\text { Viscosity } \\
\left(\mathrm{mPa} . \mathrm{s}, 55^{\circ} \mathrm{C}\right)\end{array}$ \\
\hline $0.93-0.935$ & $406.6-523.7$ & $48.32-59.37$ \\
\hline
\end{tabular}

\begin{tabular}{cccccc}
\multicolumn{7}{c}{ TABLE-2 } \\
\multicolumn{7}{c}{ CHARACTERISTICS OF CRUDE OIL } \\
UNDER RESERVOIR CONDITIONS \\
\hline $\begin{array}{c}\text { Density } \\
\left(\mathrm{g} / \mathrm{cm}^{3}\right)\end{array}$ & $\begin{array}{c}\text { Viscosity } \\
(\mathrm{mPa} . \mathrm{s})\end{array}$ & $\begin{array}{c}\text { Volume } \\
\text { factor }\end{array}$ & $\begin{array}{c}\text { Saturation } \\
\text { pressure (MPa) }\end{array}$ & $\begin{array}{c}\text { Oil-gas } \\
\text { ratio }\end{array}$ & $\begin{array}{c}\text { Acid } \\
\text { number }\end{array}$ \\
\hline $\begin{array}{c}0.8425- \\
0.8785\end{array}$ & 14.3 & 1.1037 & 12.71 & 42 & 0.4 \\
\hline
\end{tabular}

\begin{tabular}{ccccc}
\multicolumn{5}{c}{ TABLE-3 } \\
& SYNTHETIC BRINE COMPOSITION \\
\hline Total & $\mathrm{NaCl}$ & $\mathrm{MgCl}_{2}$ & $\mathrm{CaCl}_{2}$ & $\mathrm{Na}_{2} \mathrm{SO}_{4}$ \\
\hline $4.3 \mathrm{wt} \%$ & $3.44 \mathrm{wt} \%$ & $0.18 \mathrm{wt} \%$ & $0.64 \mathrm{wt} \%$ & $0.04 \mathrm{wt} \%$ \\
\hline
\end{tabular}

Rheological model: Polymer solution was assumed as a shear-thinning non-Newtonian fluid. As discussed above, the power law model ${ }^{14}$ can not accurately represent the polymer rheology behaviour in our oilfields. Meter equation ${ }^{15}$ is employed to express polymer thinning behaviour in this study, which is given in eqn. 1 .

$$
\mu_{\mathrm{p}}=\mu_{\infty}+\frac{\mu_{\mathrm{p}}^{0}-\mu_{\infty}}{1+\left(\gamma / \gamma_{1 / 2}\right)^{\mathrm{Pa}-1}}=\mu_{\mathrm{w}}+\frac{\mu_{\mathrm{p}}^{0}-\mu_{\mathrm{w}}}{1+\left(\gamma / \gamma_{1 / 2}\right)^{\mathrm{Pa}-1}}
$$

where $\mu_{\mathrm{p}}$ is apparent viscosity of polymer solution, mPa.s; $\mu_{\infty}$ is viscosity of polymer solution at infinite shear rate, mPa.s, which is simplified as brine viscosity $\left(\mu_{\mathrm{w}}\right)$ and satisfied the accuracy in our study since polymer concentration is relatively low; $\gamma_{1 / 2}$ is the shear rate at which $\mu_{p}=\left(\mu_{p}{ }^{0}+\mu_{\infty}\right) / 2, \mathrm{~s}^{-1} ; \gamma$ is the effective shear rate, $\mathrm{s}^{-1} ; \mathrm{P}_{\mathrm{a}}$ is a fitting parameter, usually $1.0<$ $\mathrm{P}_{\mathrm{a}}<1.8 ; \mu_{\mathrm{p}}{ }^{0}$ is the viscosity at very low shear rate (nearly zero), mPa.s, which is calculated by modified Flory-Huggins equation ${ }^{16}$ :

$$
\mu_{\mathrm{p}}^{0}=\mu_{\mathrm{w}}\left[1+\left(\mathrm{A}_{1} \mathrm{C}_{\mathrm{p}}+\mathrm{A}_{2} \mathrm{C}_{\mathrm{p}}^{2}+\mathrm{A}_{3} \mathrm{C}_{\mathrm{p}}^{3}\right) \mathrm{C}_{\mathrm{SEP}}^{\mathrm{SP}}\right]
$$

where $\mathrm{A}_{1},(\mathrm{~g} / \mathrm{L})^{-1}, \mathrm{~A}_{2},(\mathrm{~g} / \mathrm{L})^{-2}, \mathrm{~A}_{3},(\mathrm{~g} / \mathrm{L})^{-3}$, are fitting parameters obtained from matching experimental data, shown in Fig. 1 and Table- $4 ; \mathrm{C}_{\mathrm{p}}$ is polymer concentration, $\mathrm{g} / \mathrm{L} ; \mathrm{C}_{\mathrm{SEP}}^{\mathrm{SP}}$ represents the effect of salinity and hardness on polymer viscosity.

Rheological behaviour of polymer is significantly influenced by temperature, so the polymer solutions were prepared by mechanical stirring at $65^{\circ} \mathrm{C}$ to simulate reservoir temperature. Compared with temperature, the effect of pressure on polymer viscosity can be neglected. The tested polymer concentrations range from $100 \mathrm{mg} / \mathrm{L}(0.1 \mathrm{~g} / \mathrm{L}$ or $0.01 \mathrm{wt} \%)$ to $4000 \mathrm{mg} / \mathrm{L}$ (the polymer concentration in our field tests is $1750 \mathrm{mg} / \mathrm{L}$ ). The polymer viscosity measurement was carried

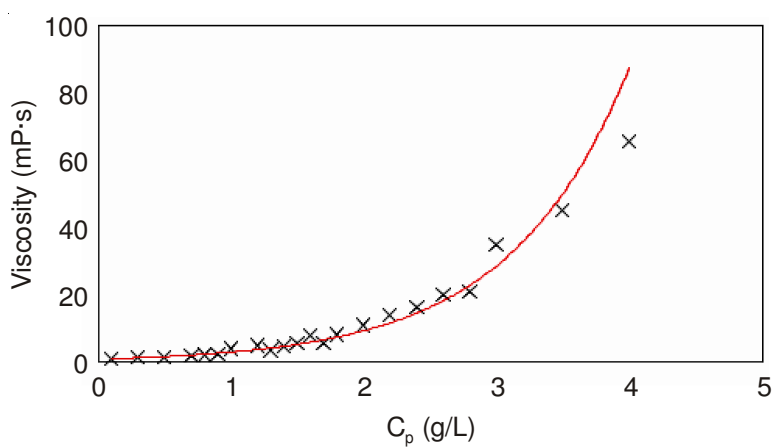

Fig. 1. Relationship between polymer solution viscosity $\left(\mu_{p}{ }^{0}\right)$ and polymer concentration $\left(\mathrm{C}_{\mathrm{p}}\right)$ at $65^{\circ} \mathrm{C}$ under $0.01 \mathrm{~s}^{-1}$ shear rate

\begin{tabular}{cccccc}
\multicolumn{7}{c}{ TABLE-4 } \\
CHARACTERISTICS OF POLYMER SOLUTIONS \\
\hline $\begin{array}{c}\mu_{\mathrm{w}} \\
(\mathrm{mPa} . \mathrm{s})\end{array}$ & $\begin{array}{c}\mathrm{A}_{1} \\
(\mathrm{~g} / \mathrm{L})^{-1}\end{array}$ & $\begin{array}{c}\mathrm{A}_{2} \\
(\mathrm{~g} / \mathrm{L})^{-2}\end{array}$ & $\begin{array}{c}\mathrm{A}_{3} \\
(\mathrm{~g} / \mathrm{L})^{-3}\end{array}$ & $\begin{array}{c}\mathrm{C}_{\mathrm{p} 0} \\
(\mathrm{~g} / \mathrm{L})\end{array}$ & $\begin{array}{c}\mathrm{D}, \\
\left(\mathrm{cm}^{2} / \mathrm{s}\right)\end{array}$ \\
\hline 0.5 & 0.634 & 0.193 & 0.921 & 1.750 & 0.0246 \\
\hline
\end{tabular}

out by Haake RS6000 rheometer made in Germany. The viscosity of polymer solutions with different concentrations was measured at $65^{\circ} \mathrm{C}$ to get the fitting numbers of $\mathrm{A}_{1}, \mathrm{~A}_{2}$ and $\mathrm{A}_{3}$, shown in Fig. 1 and Table-4. The measurements were performed under $0.01 \mathrm{~s}^{-1}$ shear rate, because $\mu_{\mathrm{p}}{ }^{0}$ is the viscosity at very low shear rate.

$\mathrm{P}_{\mathrm{a}}$ and $\gamma_{1 / 2}$ expressions are provided by CNOOC, shown in eqns. 3 and 4, respectively.

$$
\begin{gathered}
P_{a}=1.163\left(\mu_{p}^{0}\right)^{0.0311} \\
\gamma_{1 / 2}=375.1\left(\mu_{p}^{0}\right)^{-1.378}+0.0356
\end{gathered}
$$

The relationship between effective shear rate and seepage velocity is shown in eqn. $5^{17}$ :

$$
\begin{gathered}
\gamma=\frac{3 \mathrm{n}+1}{\mathrm{n}+1} \frac{10^{4} v}{\sqrt{8 \mathrm{C}^{\prime} \mathrm{K} \phi}} \\
v=\frac{\mathrm{Q}}{2 \pi \mathrm{rh}}
\end{gathered}
$$

where $\mathrm{n}$ is the bulk power law index, in the range of 0 to 1 ; $\mathrm{C}^{\prime}$ is tortuosity coefficient; $\phi$ is porosity; $\mathrm{K}$ is permeability, $\mathrm{m}^{2} ; \mathrm{Q}$ is flow rate of injected polymer solution, $\mathrm{m}^{3} / \mathrm{s} ; \mathrm{h}$ is reservoir thickness, $\mathrm{m}$; $\mathrm{r}$ is radial distance, $\mathrm{m} ; \mathrm{v}$ is seepage velocity, $\mathrm{m} / \mathrm{s}$.

During transport in porous medium, polymer concentration is also effected by convection and diffusion. Thus, polymer concentration by considering convection and diffusion is shown in eqn. $7^{18}$.

$$
\mathrm{C}_{\mathrm{p}}(\mathrm{r}, \mathrm{t})=\frac{\mathrm{C}_{\mathrm{p} 0}}{2}-\frac{\mathrm{C}_{\mathrm{p} 0}}{2} \operatorname{erf}\left[\frac{\mathrm{r}-\mathrm{Vt}}{2 \sqrt{\mathrm{Dt}}}\right]
$$

where $\mathrm{C}_{\mathrm{p} 0}$ is initial polymer concentration, $\mathrm{g} / \mathrm{L}$; $\mathrm{D}$ is diffusion coefficient, $\mathrm{m}^{2} / \mathrm{s}$.

There are several shear-thinning rheological models developed for polymer solutions. The model used in this study can accurately match the apparent viscosity of the polymer solution supplied by CNOOC over a wide range of injected flow rate, especially when polymer solutions pass through the perforation. 


\section{Well testing modeling methodology}

Newtonian-non-Newtonian composite model: During alternative polymer flooding process, the fluids in the area of polymer solutions displacement are considered as nonNewtonian fluids. However, the fluids in the area followed by water flooding are brines, which are Newtonian fluids. So the Newtonian-non-Newtonian composite model can express this kind of alternative polymer flooding (polymer flooding followed by water flooding, the sketch is shown in Fig. 2). The hypotheses are as follows: (I) The fluids of internal zone and external zone are brines and polymer solutions, respectively; (II) Brines and polymer solutions are compressible fluids; (III) Reservoir temperature is constant; (IV) Ignore pressure drop at brine-polymer interface.

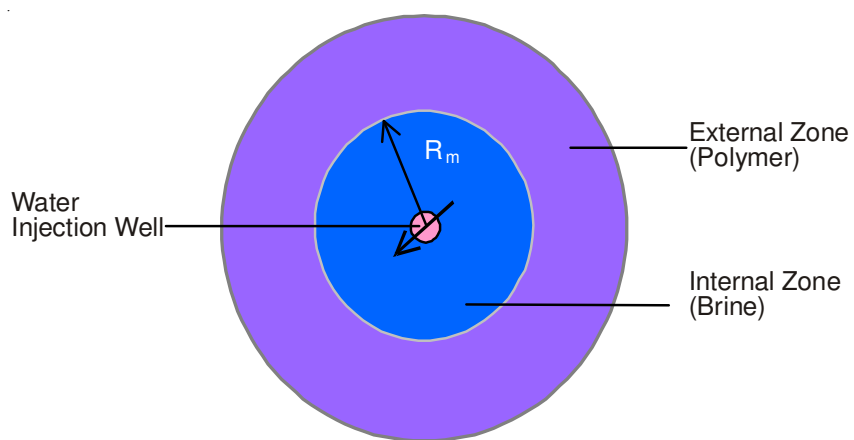

Fig. 2. Sketch of alternative polymer flooding (polymer flooding followed by water flooding)

Based on rheological model and hypothesis discussed above, establish Newtonian-non-Newtonian well testing composite model by considering skin factor and wellbore storage effect:

Percolation equation:

Internal zone: $\frac{1}{\mathrm{r}} \frac{\partial}{\partial \mathrm{r}}\left(\mathrm{r} \frac{\partial \mathrm{p}_{1}}{\partial \mathrm{r}}\right)=\left(\frac{\mu_{\mathrm{w}} \phi_{1} \mathrm{C}_{\mathrm{t} 1}}{\mathrm{~K}_{1}}\right) \frac{\partial \mathrm{p}_{1}}{\partial \mathrm{t}}\left(0<\mathrm{r} \leq \mathrm{R}_{\mathrm{m}}\right)$

External zone:

$$
\frac{1}{\mathrm{r}} \frac{\partial}{\partial \mathrm{r}}\left(\mathrm{r} \frac{1}{\mu_{\mathrm{p}}} \frac{\partial \mathrm{p}_{2}}{\partial \mathrm{r}}\right)=\left(\frac{\phi_{2} \mathrm{C}_{\mathrm{t} 2}}{\mathrm{~K}_{2}}\right) \frac{\partial \mathrm{p}_{2}}{\partial \mathrm{t}}\left(\mathrm{R}_{\mathrm{m}}<\mathrm{r}<\mathrm{r}_{\mathrm{e}}\right)
$$

Internal boundary conditions:

$$
\begin{gathered}
\mathrm{QB}=\mathrm{C} \frac{\mathrm{dp_{wf }}}{\mathrm{df}}-\left(\frac{2 \pi \mathrm{rK}_{1} \mathrm{~h}}{\mu_{\mathrm{w}}} \frac{\partial \mathrm{p}_{1}}{\partial \mathrm{r}}\right)_{\mathrm{r}=\mathrm{r}_{\mathrm{w}}} \\
\mathrm{p}_{\mathrm{wf}}-\left.\mathrm{p}\right|_{\mathrm{r}=\mathrm{r}_{\mathrm{w}}}=-\mathrm{S}\left(\mathrm{r} \frac{\partial \mathrm{p}_{1}}{\partial \mathrm{r}}\right)_{\mathrm{r}=\mathrm{r}_{\mathrm{w}}}
\end{gathered}
$$

External boundary conditions:

At brine-polymer interface:

$$
\mathrm{p}_{2}(\mathrm{r} \rightarrow \infty, \mathrm{t})=\mathrm{p}_{\mathrm{i}}
$$

$$
\begin{gathered}
\mathrm{p}_{1}\left(\mathrm{r}=\mathrm{R}_{\mathrm{m}}, \mathrm{t}\right)=\mathrm{p}_{2}\left(\mathrm{r}=\mathrm{R}_{\mathrm{m}}, \mathrm{t}\right) \\
\frac{\mathrm{K}_{1}}{\mu_{\mathrm{w}}} \frac{\partial \mathrm{p}_{1}}{\partial \mathrm{r}}\left(\mathrm{r}=\mathrm{R}_{\mathrm{m}}, \mathrm{t}\right)=\frac{\mathrm{K}_{2}}{\mu_{\mathrm{p}}} \frac{\partial \mathrm{p}_{2}}{\partial \mathrm{r}}\left(\mathrm{r}=\mathrm{R}_{\mathrm{m}}, \mathrm{t}\right)
\end{gathered}
$$

Initial conditions:

$$
\mathrm{p}_{1}(\mathrm{r}, \mathrm{t}=0)=\mathrm{p}_{2}(\mathrm{r}, \mathrm{t}=0)=\mathrm{p}_{\mathrm{i}}
$$

where $p_{i}$ is initial reservoir pressure, $\mathrm{MPa} ; \mathrm{p}_{\mathrm{wf}}$ is bottom hole pressure, $\mathrm{MPa} ; \mathrm{C}_{\mathrm{t}}$ is total compressibility, $\mathrm{MPa}^{-1}$; $\mathrm{C}$ is wellbore storage coefficient, $\mathrm{m}^{3} / \mathrm{MPa} ; \mathrm{B}$ is volume factor; $\mathrm{S}$ is skin factor, $R_{m}$ is radius of internal zone, $m$.

Dimensionless parameters are involved to solve this composite model in order to get the tendency of bottom hole pressure:

$$
\begin{gathered}
\mathrm{p}_{\mathrm{D}}=\frac{\mathrm{Kh}}{1.842 \times 10^{-3} \mathrm{Q} \mu_{\mathrm{po}} \mathrm{B}}\left(\mathrm{p}-\mathrm{p}_{\mathrm{i}}\right) \\
\mathrm{t}_{\mathrm{D}}=\frac{3.6 \mathrm{~K}}{\phi \mu_{\mathrm{po}} \mathrm{C}_{\mathrm{t}} \mathrm{r}_{\mathrm{w}}^{2}} \mathrm{t} \\
\mathrm{C}_{\mathrm{D}}=\frac{\mathrm{C}}{2 \pi \mathrm{h} \phi \mathrm{C}_{\mathrm{t}} \mathrm{r}_{\mathrm{w}}^{2}} \\
\mathrm{r}_{\mathrm{D}}=\frac{\mathrm{r}}{\mathrm{r}_{\mathrm{w}}}
\end{gathered}
$$

where $\mathrm{p}_{\mathrm{D}}$ is dimensionless pressure; $\mathrm{t}_{\mathrm{D}}$ is dimensionless time; $C_{D}$ is dimensionless wellbore storage coefficient; $r_{D}$ is dimensionless distance; $r_{w}$ is wellbore radius.

Non-Newtonian-Newtonian composite model: The fluids in the area of polymer solutions displacement are also considered as non-Newtonian fluids; however, different from Newtonian-non-Newtonian composite model, the fluids of internal zone polymer solutions which are non-Newtonian fluids. The sketch is shown in Fig. 3.

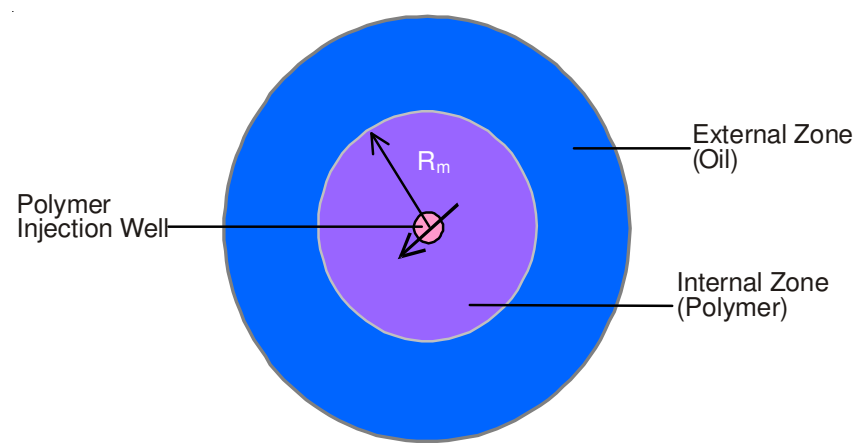

Fig. 3. Sketch of alternative polymer flooding (water flooding followed by polymer flooding)

Non-Newtonian-Newtonian well testing composite model is established as:

Percolation equation:

Internal zone:

$$
\frac{1}{\mathrm{r}} \frac{\partial}{\partial \mathrm{r}}\left(\mathrm{r} \frac{1}{\mu_{\mathrm{p}}} \frac{\partial \mathrm{p}_{1}}{\partial \mathrm{r}}\right)=\left(\frac{\phi_{1} \mathrm{C}_{\mathrm{t} 1}}{\mathrm{~K}_{1}}\right) \frac{\partial \mathrm{p}_{1}}{\partial \mathrm{t}}\left(0<\mathrm{r} \leq \mathrm{R}_{\mathrm{m}}\right)
$$

External zone:

$$
\frac{1}{\mathrm{r}} \frac{\partial}{\partial \mathrm{r}}\left(\mathrm{r} \frac{\partial \mathrm{p}_{2}}{\partial \mathrm{r}}\right)=\left(\frac{\mu_{0} \phi_{2} \mathrm{C}_{\mathrm{t} 2}}{\mathrm{~K}_{2}}\right) \frac{\partial \mathrm{p}_{2}}{\partial \mathrm{t}}\left(\mathrm{R}_{\mathrm{m}}<\mathrm{r}<\mathrm{r}_{\mathrm{e}}\right)
$$

Internal boundary conditions:

$$
\mathrm{QB}=\mathrm{C} \frac{\mathrm{dp}_{\mathrm{wf}}}{\mathrm{dt}}=\left(\frac{2 \pi \mathrm{rK}_{1} \mathrm{~h}}{\mu_{\mathrm{p}}} \frac{\partial \mathrm{p}_{1}}{\partial \mathrm{r}}\right)_{\mathrm{r}=\mathrm{r}_{\mathrm{w}}}
$$




$$
\mathrm{p}_{\mathrm{wf}}-\left.\mathrm{p}\right|_{\mathrm{r}=\mathrm{r}_{\mathrm{w}}}=-\mathrm{S}\left(\mathrm{r} \frac{\partial \mathrm{p}_{1}}{\partial \mathrm{r}}\right)_{\mathrm{r}=\mathrm{r}_{\mathrm{w}}}
$$

External boundary conditions:

$$
\mathrm{p}_{2}(\mathrm{r} \rightarrow \infty, \mathrm{t})=\mathrm{p}_{\mathrm{i}}
$$

At oil-polymer interface:

$$
\begin{gathered}
\mathrm{p}_{1}\left(\mathrm{r}=\mathrm{R}_{\mathrm{m}}, \mathrm{t}\right)=\mathrm{p}_{2}\left(\mathrm{r}=\mathrm{R}_{\mathrm{m}}, \mathrm{t}\right) \\
\frac{\mathrm{K}_{1}}{\mu_{\mathrm{p}}} \frac{\partial \mathrm{p}_{1}}{\partial \mathrm{r}}\left(\mathrm{r}=\mathrm{R}_{\mathrm{m}}, \mathrm{t}\right)=\frac{\mathrm{K}_{2}}{\mu_{0}} \frac{\partial \mathrm{p}_{2}}{\partial \mathrm{r}}\left(\mathrm{r}=\mathrm{R}_{\mathrm{m}}, \mathrm{t}\right)
\end{gathered}
$$

Initial conditions:

$$
\mathrm{p}_{1}(\mathrm{r}, \mathrm{t}=0)=\mathrm{p}_{2}(\mathrm{r}, \mathrm{t}=0)=\mathrm{p}_{\mathrm{i}}
$$

The dimensionless parameters are the same as above.

\section{RESULTS AND DISCUSSION}

Based on dimensionless pressure and dimensionless pressure derivative, obtain the typical curves of pressure and pressure derivative in log-log scale.

Newtonian-non-Newtonian composite model: Typical curves of Newtonian-non-Newtonian composite model under different kinds of boundary conditions (infinite boundary, constant pressure boundary and closed boundary) by considering shear rate, convection and diffusion are shown in Fig. 4(a).
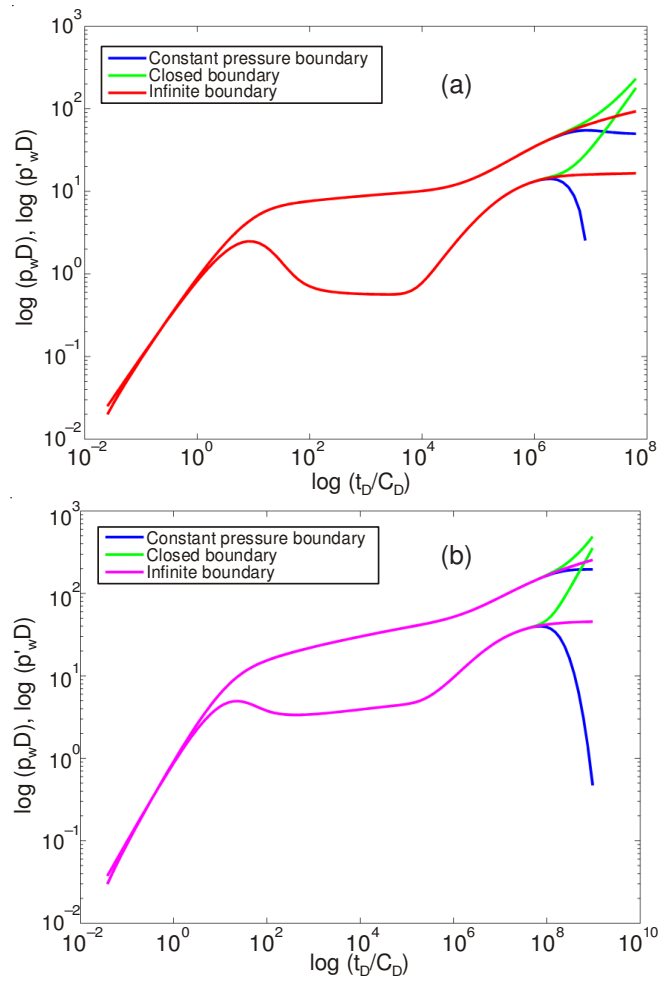

Fig. 4. Typical curves of composite model under three kinds of boundary conditions: (a) Newtonian-non-Newtonian; (b) non-NewtonianNewtonian

The typical curves have five sections: (I) wellbore storage section (the curves of pressure and pressure derivative overlap); (II) transient section (transition from wellbore storage section to radial flow section); (III) internal radial flow section (pressure derivative curve is horizontal with value of 0.5 ); (IV) water-polymer transient section; (V) combination section (effected by internal zone and external zone at the same time). Effect of boundary conditions mainly reflect in combination section (V): under infinite boundary condition, the curves slightly move upward due to the external polymer solutions (since viscosity of polymer solution is higher than brine viscosity, resulting in lower mobility and higher sweep efficiency, which is the key point for polymer flooding EOR); the pressure curve and pressure derivative curve both move upward sharply with closed boundary; under constant pressure boundary condition, the pressure curve becomes horizontal but the pressure derivative curve decreases dramatically.

The effect of initial polymer concentration on typical curves under infinite boundary condition is shown in Fig. 5(a). The higher polymer concentration, the higher of polymer solutions viscosity (Fig. 1), more flow resistance from internal zone to external zone, resulting in greater upward amplitude of the curves in water-polymer transient section (IV) and of the pressure curve in combination section (V). Although the pressure derivative curve in combination section $(\mathrm{V})$ is horizontal, the value of pressure derivative increases with initial polymer concentration due to more flow resistance. Since the fluids of internal zone are brines, the polymer concentration cannot influence section I, II, III.
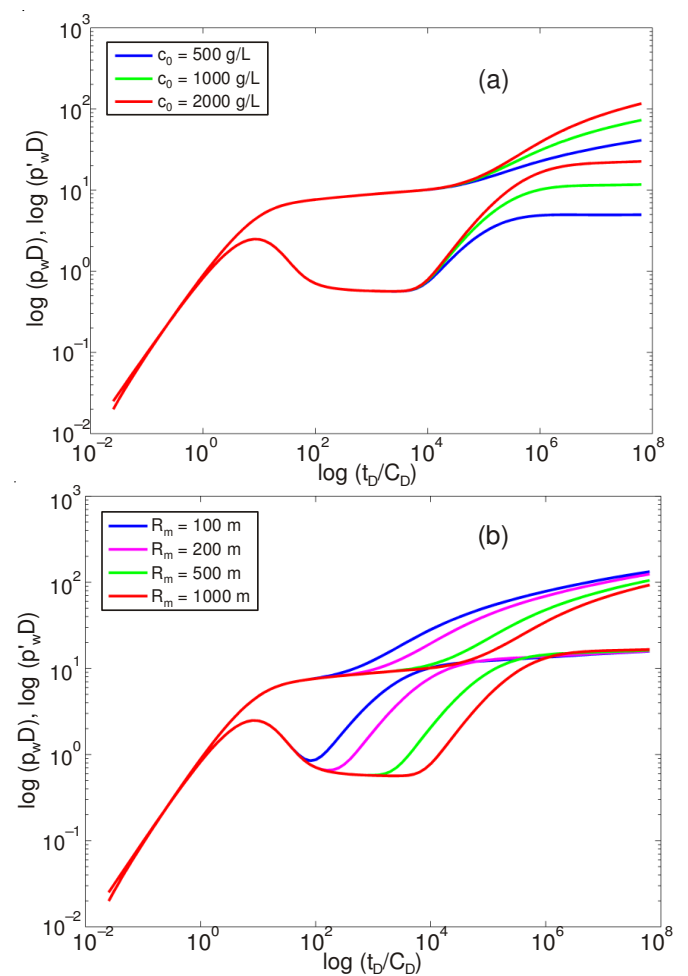

Fig. 5. Typical curves of Newtonian-non-Newtonian composite model under infinite boundary condition: (a) effect of initial polymer concentration; (b) effect of internal zone radius

The effect of internal zone radius on typical curves under infinite condition is shown in Fig. 5(b). Internal zone radius indicates the duration of water flooding and the volume that water flooding sweeps. The bigger internal zone radius, the longer duration of internal radial flow section (III) and waterpolymer transient section (IV) appears later. However, the pressure and pressure derivative curves are convergent over time in combination section (V), since mobility is not affected by internal zone radius. 
Non-Newtonian-Newtonian composite model: Typical curves of Non-Newtonian-Newtonian composite model under different kinds of boundary conditions (infinite boundary, constant pressure boundary and closed boundary) by considering shear rate, convection and diffusion are shown in Fig. 4(b). The typical curves also have five sections: sections (I), (II), (III) are the same as Fig. 4(a); (IV) polymer-oil transient section; (V) combination section. The typical curves are similar to that of Newtonian-non-Newtonian composite model, however, the curves in internal radial flow section (III) present a slope due to the polymer solutions of internal zone. Effect of boundary conditions is also similar to Newtonian-nonNewtonian composite model.

The effect of polymer concentration (internal zone) on typical curves under infinite boundary condition is shown in Fig. 6(a). Higher polymer concentration results in greater upward amplitude of curves in internal radial flow section (III) but less upward amplitude of curves in polymer-oil transient section (IV), due to higher polymer viscosity and constant oil viscosity which decrease the mobility ratio.
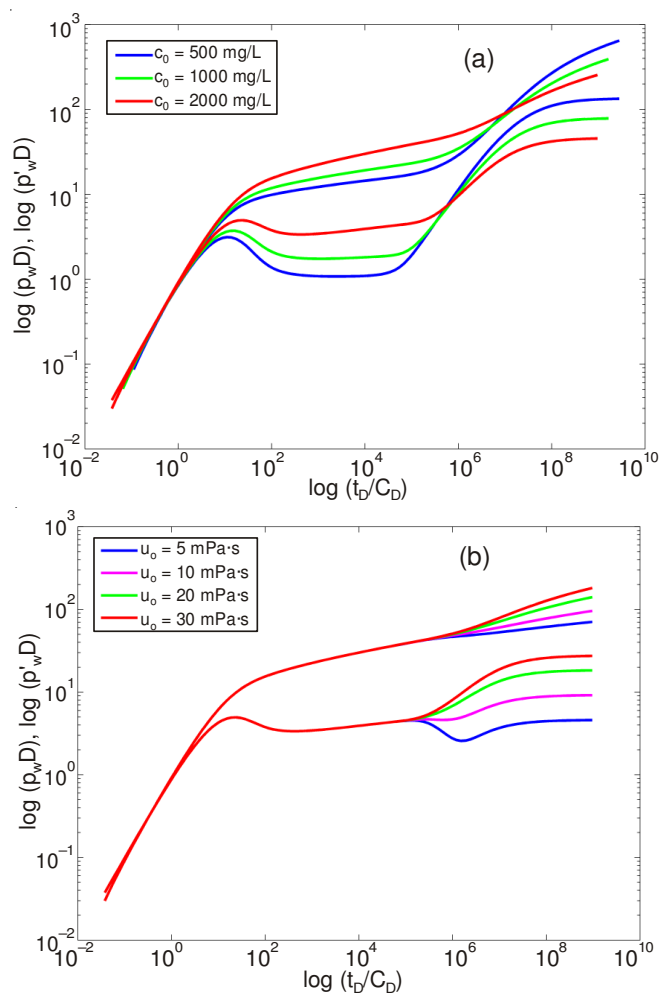

Fig. 6. Typical curves of non-Newtonian-Newtonian composite model under infinite boundary condition: (a) effect of initial polymer concentration; (b) effect of oil viscosity

The effect of oil viscosity (external zone) on typical curves under infinite boundary condition is shown in Fig. 6(b). For low viscosity oil (lower than polymer viscosity), the pressure derivative curve moves downward in the polymer-oil transient section (IV), due to less flow resistance from internal zone to external zone; for high viscosity oil (higher than polymer viscosity), the upward amplitude of pressure derivative curve increases with the increase of oil viscosity.

Field well testing interpretation: Interpret the field test data by using our composite model, the interpretation method and procedure are as followed:
- Choose model according to flooding characteristics of injection well. Newtonian-non-Newtonian composite model is employed for polymer flooding followed by water flooding; for water flooding followed by alternative polymer flooding, choose non-Newtonian-Newtonian composite model.

- Draw pressure data of field test in log-log scale and perform history matching with typical curves to calculate the average formation pressure, internal zone permeability, external zone permeability, skin factor, wellbore storage coefficient and internal zone radius.

Field test one: Polymer flooding followed by water flooding: This field well testing is based on pressure drawdown process and basic parameters of well and reservoir are shown in Table-5.

TABLE-5

BASIC PARAMETERS OF WELL AND

RESERVOIR OF FIELD TEST ONE

\begin{tabular}{lcc}
\hline Injection rate & $\mathrm{q}\left(\mathrm{m}^{3} / \mathrm{d}\right)$ & 100 \\
Reservoir thickness & $\mathrm{h}(\mathrm{m})$ & 10 \\
Oil volume factor & $\mathrm{B}_{\mathrm{o}}$ & 1.1 \\
Porosity & $\phi$ & 0.3 \\
Crude oil viscosity & $\mu_{\mathrm{o}}(\mathrm{mPa} . \mathrm{s})$ & 14.3 \\
Brine viscosity & $\mu_{\mathrm{w}}(\mathrm{mPa} . \mathrm{s})$ & 0.5 \\
Total compressibility & $\mathrm{C}_{\mathrm{t}}(1 / \mathrm{MPa})$ & 0.0014 \\
Wellbore radius & $\mathrm{r}_{\mathrm{w}}(\mathrm{m})$ & 0.1 \\
\hline
\end{tabular}

The injection well is polymer flooding followed by water flooding, so Newtonian-non-Newtonian composite model is used for well testing interpretation and field testing history matching. The history matching curves and field testing data are shown in Fig. 7(a) and the interpretation results are shown in Table-6, which indicate that our model can accurately interpret field testing one and evaluate formation.
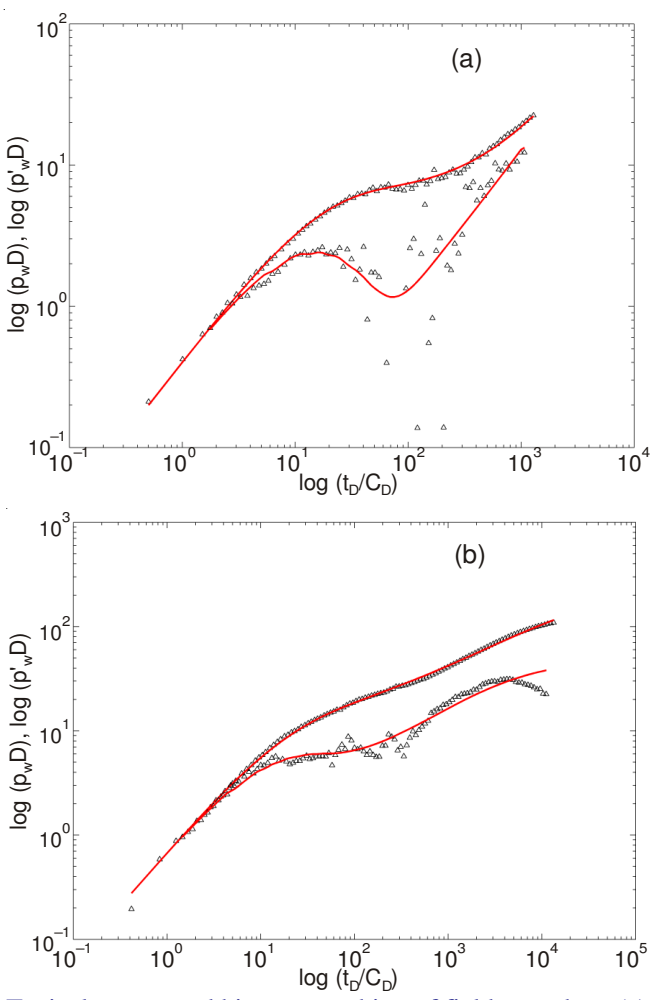

Fig. 7. Typical curves and history matching of field tests data: (a) field test one; (b) field test two 
TABLE-6

INTERPRETATION RESULTS OF FIELD TEST ONE

\begin{tabular}{lcc}
\hline Average reservoir pressure & $\mathrm{MPa}$ & 18.75 \\
Internal zone permeability & $\mu \mathrm{m}^{2}$ & 1.79 \\
Skin factor & - & 2.18 \\
Wellbore storage coefficient & $\mathrm{m}^{3} / \mathrm{MPa}$ & 1.82 \\
External zone permeability & $\mu \mathrm{m}^{2}$ & 1.28 \\
Internal zone radius & $\mathrm{m}$ & 65.51 \\
\hline
\end{tabular}

Field test two: Water flooding followed by alternative polymer flooding: The basic parameters of well and reservoir are shown in Table-7.

\begin{tabular}{lcc}
\multicolumn{3}{c}{ TABLE-7 } \\
\multicolumn{3}{c}{ BASIC PARAMETERS OF WELL AND } \\
\multicolumn{1}{c}{ RESERVOIR OF FIELD TEST TWO } \\
\hline Injection rate & $\mathrm{q}\left(\mathrm{m}^{3} / \mathrm{d}\right)$ & 92.6 \\
Reservoir thickness & $\mathrm{h}(\mathrm{m})$ & 11.2 \\
Oil volume factor & $\mathrm{B}_{\mathrm{o}}$ & 1.1 \\
Porosity & $\phi$ & 0.28 \\
Crude oil viscosity & $\mu_{\mathrm{o}}(\mathrm{mPa} . \mathrm{s})$ & 14.3 \\
Brine viscosity & $\mu_{\mathrm{w}}(\mathrm{mPa} . \mathrm{s})$ & 0.5 \\
Total compressibility & $\mathrm{C}_{\mathrm{t}}(1 / \mathrm{MPa})$ & 0.0014 \\
Wellbore radius & $\mathrm{r}_{\mathrm{w}}(\mathrm{m})$ & 0.1 \\
\hline & &
\end{tabular}

\begin{tabular}{lcc}
\multicolumn{3}{c}{ TABLE-8 } \\
\multicolumn{2}{c}{ INTERPRETATION RESULTS OF FIELD TEST TWO } \\
\hline Average reservoir pressure & $\mathrm{MPa}$ & 17.6 \\
Internal zone permeability & $\mu \mathrm{m}^{2}$ & 1.35 \\
Skin factor & - & 1.2 \\
Wellbore storage coefficient & $\mathrm{m}^{3} / \mathrm{MPa}$ & 3.7 \\
External zone permeability & $\mu \mathrm{m}^{2}$ & 1.21 \\
Internal zone radius & $\mathrm{m}$ & 99.2 \\
\hline
\end{tabular}

The injection well is water flooding followed by alternative polymer flooding, so non-Newtonian-Newtonian composite model is used for well testing interpretation and field testing history matching. The history matching curves and field testing data are shown in Fig. 7(b) and the interpretation results are shown in Table-8, which further prove that our model can accurately interpret field testing two for formation evaluation.

\section{Conclusion}

This paper established two kinds of composite models for well testing in polymer flooding reservoirs based on a rheological model by considering shear rate, diffusion and convection. Typical curves of numerical well testing were also obtained. The main conclusions drawn from this study are as follows: Typical curves have five section: (I) wellbore storage section; (II) transient section (transition from wellbore storage section to internal radial flow section); (III) internal radial flow section; (IV) transient section (transition between internal fluids and external fluids); (V) combination section. For Newtonian-non-Newtonian composite model: higher polymer concentration, more flow resistance from internal zone to external zone, resulting in greater upward amplitude of the curves in water-polymer transient section (IV) and of the pressure curve in combination section $(\mathrm{V})$; bigger internal zone radius, longer duration of internal radial flow section (III) and water-polymer transient section (IV) appears later, meanwhile, the pressure and pressure derivative curves are convergent in combination section (V) over time. For non-Newtonian-
Newtonian composite model: higher polymer concentration results in greater upward amplitude of curves in internal radial flow section (III) but less upward amplitude of curves in polymer-oil transient section (IV), due to mobility ratio decreases. For low viscosity oil (lower than polymer viscosity), the pressure derivative curve moves downward in the polymeroil transient section (IV), due to less flow resistance from internal zone to external zone; for high viscosity oil (higher than polymer viscosity), the upward amplitude of pressure derivative curve increases with increasing oil viscosity. Two field tests indicate that our composite models can accurately describe the dynamic characteristics of polymer flooding. The interpretation results are significant for oil companies to evaluate formation and adjust production: In these two cases, the internal permeability and external permeability are not reduced too much compared with those of before polymer flooding and the skin factors are not high, indicating formation damage due to polymer flooding is less and there is no need for acidizing; locate the new well to improve production according to the internal zone radius, which indicates the polymer flooding frontier.

\section{ACKNOWLEDGEMENTS}

The authors gratefully acknowledged the financial support from Science Foundation of China University of Petroleum, Beijing (No. YJRC-2013-41), National Natural Science Foundation of China (No. 51304223), National Science and Technology Major Projects (No. 2011ZX05024-004-07, No. 2011ZX05009-005-01C).

\section{REFERENCES}

1. W. Zhang and X. Hou, Polym. Adv. Technol., 10, 465 (1999).

2. L. Piculell, K. Thuresson and B. Lindman, Polym. Adv. Technol., 12, 44 (2001).

3. T. Barroso, R. Viveiros, M. Coelho, T. Casimiro, A.M. Botelho do Rego and A. Aguiar-Ricardo, Polym. Adv. Technol., 23, 1381 (2012).

4. H. Yu, C. Kotsmar, K.Y. Yoon, D.R. Ingram, K.P. Johnston, S.L. Bryant and C. Huh, SPE paper 129887, Society of Petroleum Engineers (SPE): Tulsa, OK (2010)

5. T. Zhang, M. Murphy, H. Yu, H.G. Bagaria, K.Y. Yoon, B.M. Nielson, C.W. Bielawski, K.P. Johnston, C. Huh and S.L. Bryant, SPE paper 166346, Society of Petroleum Engineers (SPE): New Orleans, LA, (2013).

6. B.S. Shiran and A. Skauge, Energy Fuels, 27, 1223 (2013).

7. X. Wang and Y. Gu, Ind. Eng. Chem. Res., 50, 2388 (2011).

8. N.B. Wyatt, C.M. Gunther and M.W. Liberatore, Polymer, 52, 2437 (2011).

9. L.W. Lake, Enhanced Oil Recovery, Prentice Hall: CA, USA, edn. 1 (1996).

10. C.U. Ikoku and H.J. RameyJr., SPE J., 19, 164 (1979).

11. K. Song, L. Wang and B. Ji, Acta Petrol.Sin., 17, 82 (1996).

12. K. Song, J. Zhu, Z. Liu, Z. Sun and Y. Wang, Acta Petrol. Sin., 18, 78 (1997).

13. S.K. Veerabhadrappa, J.J. Trivedi and E. Kuru, Ind. Eng. Chem. Res., 52, 6234 (2013).

14. R.B. Bird, W.E. Steward and E.N. Lightfoot, Transport Phenomena, John Wiley\& Sons: New York, USA.

15. D.M. Meter and R.B. Bird, AIChE J., 10, 878 (1964).

16. P.G. Flory, Principles of Polymer Chemistry, Cornell University Press: Ithaca, New York, USA (1953).

17. X. Wang, Petrol Explor. Develop.,3, 69 (1990).

18. J. Wang, Physic-Chemical Fluid Mechanics and Application in Chemical EOR, Petroleum Industry Press: Beijing, China (2008). 